\title{
QUAL METODOLOGIA PARA UMA CRIMINOLOGIA CRÍTICA? // Dan
}

\section{Kaminski ${ }^{1}$}

\section{Palavras-chave}

metodologia crítica / técnica de entrevista qualitativa / sociologia do descompasso

HIIIIIIIIIIIIIIIIIIIIIIIIIIIIIIIII

\section{Sumário}

\section{Introdução}

1 O sociólogo e os magistrados : crítica do interrogatório

2 A confusão entre a missão e a atividade: crítica da sociologia do descompasso

3 O que é condenar? O que "condenar" faz dizer

4 In cauda venenum: de volta à distancia social

Referências

\section{Resumo}

Este ensaio propõe uma abordagem teórico-metodológica que visa fornecer elementos para pensar uma metodologia possível para a criminologia crítica. Sem realizar a polarização « macro-micro » à qual participa a criminologia crítica, pretende-se observar e analisar duas posturas diferentes de pesquisa que utilizam a entrevista com juízes como método de coleta de dados: uma, que pretende arrancar a verdade dos atores, abordados em um processo de cunho investigativo, e, outra, que visa conhecer, numa perspectiva de cunho empático-indutivo, o ponto de vista desses atores diante de uma necessidade eventual de desvendamento de suas práticas. Realiza-se uma crítica ao que podemos chamar de "sociologia do descompasso" e seu projeto correcionalista. Desta maneira, mais do que simplesmente medir e corrigir os descompassos de uma atividade observada, situamos o pesquisador como alguém que pretende compreender o descompasso e entender como os atores lidam com as normas que orientam as suas ações, e, como esses atores as justificam. Destacam-se neste ensaio: o modo como se observa a intersubjetividade na entrevista, o tipo de relação que se pretende ter em um processo de pesquisa, e a própria capacidade reflexiva da sociologia (de observar a si mesma neste processo).
1 Texto originalmente submetido em francês. Tradução de Ana Miria dos Santos Carvalho Carinhanha. Professor da École de Criminologie de l'Université Catholique de Louvain (Bélgica). Membro do Centre de recherche interdisciplinaire sur la déviance et la pénalité. Email: dan.kaminski@uclouvain.be 


\section{WHICH METHODOLOGY FOR A CRITICAL CRIMINOLOGY? // Dan}

\section{Kaminski}

\section{Keywords:}

Critical methodology / qualitative interviews technique / sociology of the gap

HIIIIIIIIIIIIIIIIIIIIIIIIIIIIIIIIII

\section{Abstract}

This essay proposes a theoretical-methodological perspective that strives to provide elements to imagine a viable methodology for critical criminology. Without going into the "macro-micro" polarization in which critical criminology is part of, we intend to observe and analyze two different research approaches that use interviews with judges as techniques of data collection: one, which seeks to find truth from the actors that are part of an investigative process, and another one, designed to understand, within a empathic-inductive perspective, the point of view of the actors before the eventual need to bring to light their practices. We criticize what we call "sociology of the gap" and its correctional project. Thus, more than only measuring and correcting the gap of an observed activity, we situate the researcher as someone who aspires to understand the gap and learn how the actors deal with the rules that guide their actions, and how they justify them. This article highlights: the way in which one can observe intersubjectivity in interviews, the kind of relationship that one aspires to have in a research process, and sociology's reflexive capability (to understand itself within this process). 


\section{Introdução}

A polarização "macro-micro" da qual participa a criminologia crítica (efeitos estruturais da raça, da classe, de gênero) me parece problemática se ela não abre caminho para as condições "micro" de produção dos seus efeitos ${ }^{2}$. É difícil escapar de um certo profetismo, de um evolucionismo (esse da revolução programável) ao contrário a invocar a lei da inércia, quando nos contentamos com uma posição macrossociológica. Um ponto muito significativo das evoluções sociológicas francesas dos últimos trinta anos diz respeito à articulação macro-micro. A partir do macro: como se experimentam nas microrrelações os efeitos da classe, da raça e do gênero? A partir do micro: como se encontram, observando as relações sociais e prosseguindo de forma indutiva, os efeitos de estrutura relativos à classe, à raça e ao gênero? Em suma, a distinção macro-micro deveria apenas servir para identificar um ponto de partida da pesquisa, não um projeto radicalmente distinto ou manco. 0 que evoco aqui é, portanto, o embrião de uma sociologia bem mais antiga que aquela dos anos 1980. Simmel, no início do século XX, já considerava que as formas sociais emergiam das ações individuais e que, uma vez constituídas, essas formas agiam sobre o indivíduo. É o que sustenta a sociologia da tradução (Akrich, Callon, Latour, 2006), quando ela considera que a estabilização das formas da vida social deve ser considerada mais como um ponto de chegada do que de partida.

Ser capaz de articular o peso das estruturas e a força das ações e das representações apresenta um benefício precioso: tal articulação indica que uma desarticulação, isto é, uma mudança, é possível. O papel da linguagem nesse caso tornou-se essencial: a linguagem é uma estrutura, mas ela contém recursos de uso, de criação e de inovação. É nesse sentido que me interesso ao ato de justificar, entendido como operação de linguagem de apresentação das práticas, não para descrevê-las, mas para dar-lhes um sentido (uma direção e uma significação) que não se deduz necessariamente ou somente da estrutura (de domi-

2 Esse artigo é oriundo de uma conferência proferida, com o mesmo título, na Universidade Federal do Rio de Janeiro, em 3 de outubro de 2016, a convite do professor José Roberto Xavier em parceria com o Grupo de pesquisa em criminologia (GPCrim) da UNEB/ UEFS. Agradeço a José Roberto Xavier, Fernanda Prates e Riccardo Cappi pelo convite, e a Ana Míria Carinhanha pela tradução. nação). Postulo então que as práticas são pelo menos parcialmente estrangeiras aos recursos estruturais da dominação ${ }^{3}$. Dessa forma, interessa-me a potencial heterogeneidade entre a justificação das práticas (audível na entrevista de pesquisa) e os efeitos das práticas (discriminatórias em termos de classe, de raça, de gênero). Isso permite desunificar as pessoas: G.H. Mead já considerava "uma personalidade múltipla" como normal. Além das caixas-pretas dos sistemas, é necessário considerar as caixas-pretas das pessoas, nas quais se constroem os regimes de justificação $0^{4}$ que os sujeitos são capazes de construir e de descontruir. Levar a sério as palavras dos "poderosos" - como a "lei da economia", a "natureza feminina", o "caráter inescapável do desemprego", a "única alternativa possível" (TINA - there is no alternative), "as necessidades jurídicas ou técnicas" - e pedir-lhes que atribuam razões a essas expressões, leva-os a se justificarem, a perceber suas fissuras e fraquezas, o que pode abrir o espaço de possibilidades em favor do "dominado" (Corcuff, 2007, 118).

O defeito da perspectiva crítica que ressalto aqui não tem nada a ver com o apagamento dos sujeitos ou autores em uma tal perspectiva, mas, bem antes, com a ausência da consideração pela maneira como esses sujeitos individuais lidam com as estruturas que não são nem totalmente determinantes nem, é claro, impertinentes. Os sujeitos se posicionam nas estruturas desenvolvendo registros de justificação de suas ações ou inações, assim como de suas crenças. A subjetivação (Foucault) e a justificação (Boltanski) são, portanto, suportes úteis para a análise ascendente do poder do qual uma parte é evidentemente imposta de cima para baixo.

Luc Boltanski lembra oportunamente a dificuldade da sociologia, às vezes partida entre crítica e método:

\footnotetext{
3 Weller (1994) mostra que o recurso às entrevistas (ver também Monjardet, 1996) favorece uma visão coerente e estável da pessoa, ao passo que a observação direta e contínua de suas atividades traz uma visão heterogênea. Essa heterogeneidade pode ser observada a um segundo nível no interior da própria entrevista.

4 Apoiando-me em Boltanski e Thévenot (1991), chamo de justificação o modo como as pessoas constroem a legitimidade ao combinar (segundo duas grandezas diferentes) duas condições: a da humanidade comum e a de uma ordem na humanidade.
} 
"A neutralidade exigida do sociólogo é de ordem metodológica, não de ordem política. (...) A sociologia sempre foi uma disciplina (...) que teve uma ancoragem crítica e que procurou meios para ajustar uma posição metodologicamente neutra com a possibilidade de uma crítica social, ainda que toda a dificuldade resida nesta articulação" (Boltanski, 2013, p. 55-56).

Em vista dessa dificuldade, o projeto de estudar a justiça pode ser denunciador e ignorar qualquer conhecimento. Nesse caso, trata-se de denunciar o que nós não conhecemos, posição justificada por um desprezo tanto pelo objeto da pesquisa quanto pela trajetória empírica que permitiria a sua aproximação. Nesse sentido, G. de Lagasnerie (2016) oferece um exemplo em sua versão mais grotesca. 0 projeto pode ainda consistir em denunciar a partir do conhecimento. A postura de Rémy Lenoir (1996), que será abordada abaixo, ilustra tal projeto, que obriga o sociólogo a arrancar a verdade dos atores que ele encontra. Finalmente, o sociólogo pode procurar conhecer, esse conhecimento uma vez adquirido suscitando indutivamente uma necessidade eventual de desvelamento. Minha posição assim resumida será desenvolvida e ilustrada nas linhas que se seguem.

O pesquisador que realiza entrevistas com juízes, policiais, ou membros do sistema penitenciário teria o papel de descobrir o que esses interlocutores não sabem ou procuram esconder? Como sugere Jean-Pierre Olivier de Sardan (2008), a entrevista oscila entre a consulta dos conhecimentos e a consulta da experiência/expertise do interlocutor. Em outras palavras, precisamos dos atores penais para conhecer suas práticas e suas lógicas, assim como para torná-las conhecidas. Assim sendo, o desvelamento crítico, concebido como objetivo da prática do pesquisador, depende de uma extração ou de uma oferta de comunicação?

\section{O sociólogo e os magistrados : crítica do interrogatório}

Rémi Lenoir, autor do artigo publicado na Genèses (1996) e intitulado Le sociologue et les magistrats. Entretiens sur la mise en détention préventive ( $\mathrm{O}$ sociólogo e os magistrados. Entrevistas sobre a detenção preventiva), realizou entrevistas com juízes em um contexto bastante tenso em decorrência das reformas contra as quais os juízes entraram em disputa. Desconfiança, prudência, obstáculos, resistências aparecem para o sociólogo que, desde o primeiro subtítulo de seu artigo, se atribui o status de estrangeiro. O seu relato sobre o primeiro contato com os entrevistados já é revelador:

"A lentidão das respostas, as numerosas chamadas telefônicas e as respostas evasivas das secretárias eletrônicas, a procrastinação dos magistrados, os adiamentos, a dispersão temporal dos compromissos, constituíam para o pesquisador indícios de resistência a esta investigação. Além disso, a escolha dos critérios que levaram à seleção, por sua hierarquia, dos juízes que 'aceitaram' ser entrevistados, não me foi especificada e qualquer questionamento sobre este assunto teria sido impróprio" (Lenoir, 1996).

Rémi Lenoir (1996) acrescenta que a dificuldade também se deveu ao fato de que os magistrados "o receberam, é claro, pela sua qualificação, mas também porque teriam recebido ordens de seus superiores", sem mencionar as recomendações recebidas para dizer o mínimo possível. Lenoir observa, assim, que "o entrevistado procura por todos os meios escapar de uma relação que o implicasse e o obrigasse a ir além das conveniências burocráticas".

A entrevista em si aprofunda o desconforto. Lenoir analisa as respostas obtidas de uma magistrada que "atesta, ao mesmo tempo, sinais de desinteresse, aborrecimento e cansaço diante de alguém que o incomodou em seu trabalho e que o forçou a questionar-se sobre pontos que, em sua profissão, ela regula de maneira prática, 'sem fazer todas essas questões', que lhe parecem inúteis, chatas e supérfluas". A partir da atitude de uma juíza entrevistada, ele conclui: "eu deveria representar para ela a seriedade (acadêmica), mas também a futilidade (a sociologia)". A entrevista é então considerada "perdida" por conta de uma atitude - da entrevistada, é claro - que "impediu sobretudo esse tipo de acompanhamento do pensamento, característico da entrevista; essa capacidade de se 'colocar em pensamento no lugar' do entrevistado, para usar a expressão de Pierre Bourdieu" (Lenoir, 1996). A fórmula de Pierre Bourdieu (1993, p. 910) deve ser bem 
compreendida; ela é mais precisamente "colocar-se em seu lugar em pensamento" e indica a capacidade que o sociólogo deve ter para lidar precisamente com a distância social que o separa de seus entrevistados; estamos longe da leitura segundo a qual se trataria de uma questão de pensar no lugar do outro, considerado como um idiota cultural (mesmo que Bourdieu pudesse, em outras comunicações, deixar entender que essa interpretação não seria talvez incongruente). Outra resistência descrita por Lenoir: o discurso conveniente, auxiliado pela referência à lei, é um obstáculo à conivência que "supõe, por parte das pessoas interrogadas, que elas encontrem um interesse para elas em se fazer questionar pelo pesquisador sobre o assunto que ele lhes propõe". A dificuldade do pesquisador surge do fato de que os entrevistados não se colocam as mesmas perguntas que ele. Nessa perspectiva, o sociólogo não concebe e nem sente uma "cooperação" real de seu interlocutor até que uma conivência apareça, "uma condição sine qua non para revelar as estruturas perceptivas e cognitivas" em funcionamento no trabalho de tomada de decisão do juiz. É somente nessas condições, continua Lenoir, que se pode alcançar e ouvir um ressentimento doloroso sentido em relação ao "estabelecimento judiciário". É perturbador entender que a conivência das respostas não repousa apenas sobre o fato de nos colocarmos as mesmas questões, mas também sobre o fato de que nós partilharíamos das mesmas respostas.

Lenoir aprofunda a necessidade da conivência ao testemunhar que ela também é

“impedida pela preocupação do magistrado em manter o controle da interpretação": "tudo acontece como se todos estivessem de guarda, tanto o investigador como o investigado, o que não é nada propício para uma pesquisa de tipo etnográfico que pressupõe uma presença contínua, uma conivência participativa por parte do magistrado. O juiz, assim que saímos do caminho mais conhecido da problemática instituída, fica em posição defensiva, não tendo mais a sensação de controlar a situação da investigação" (Lenoir, 2016)

Depois de uma ilustração, Lenoir conclui: "A questão da interação entre essas duas categorias de especialistas em interrogatórios é ter tomado para si a defini- ção do problema e tentar impô-la ao outro". Aqui está o sociólogo promovido ao posto de "especialista em interrogatório". Levemos a sério, momentaneamente, esse nivelamento da entrevista ao interrogatório: ele pressupõe que algumas respostas são esperadas pelo pesquisador, como um policial que é movido pela hipótese de obtenção de uma confissão de um suspeito. Que o magistrado suspeite do sociólogo que vem questioná-lo é uma coisa, mas que o sociólogo se conceba ele mesmo na posição de interrogador (o que a palavra investigação vem reforçar), existe aqui algo... a se questionar.

Lenoir finalmente fornece a chave para o "sucesso" da entrevista: "as entrevistas mais bem-sucedidas são provavelmente com magistrados que às vezes têm 'problemas com a justiça', quaisquer que sejam os motivos, e, ao mesmo tempo, acreditam completamente em sua missão". Esses juízes que têm um problema com a justiça compartilham, contudo, "o senso comum judiciário". O objetivo do pesquisador torna-se claramente o de fazer expressar o inexprimível. O solilóquio (monólogo) sofrido e o humor (ironia, escárnio e auto-desaprovação) tornam-se os sintomas expressivos da "má consciência" dos magistrados que suportam os valores e as formulações da instituição, testemunhando a distância crítica emitida sobre as condições e as atividades concretas de trabalho que se afastam desses valores e fórmulas.

\section{A confusão entre a missão e a atividade: crítica da sociologia do descompasso}

Debrucei-me sobre esse texto e seu autor apenas para fins "pedagógicos" destinados a reverter um pouco a observação feita pelo sociólogo de seus investigados em uma auto-observação do próprio sociólogo. A reflexividade de Lenoir sobre sua metodologia limita-se a um questionamento sobre as condições de produção da conivência para extrair confissões sobre, por um lado, o descompasso entre valores institucionais e normas jurídicas e, por outro lado, sobre práticas dificilmente justificáveis no direito ou discriminatórias. A este respeito, a atitude geral do pesquisador é esta do especialista em interrogatórios que, se nos mudarmos da fórmula de Bourdieu, pensa no lugar do entrevistado em vez de se mostrar capaz de "estar em pensamento em seu lugar". 
Gostaria de colocar em paralelo a análise metodológica de Lenoir com um trabalho que eu, muito mais modestamente que ele, conduzi igualmente com magistrados. Ao fazer uma pergunta simples aos juízes penais belgas ("o que é condenar?"), eu criei, a partir de uma perspectiva crítica, as condições de uma disputa e, portanto, de uma exigência de justificação, que me pareceu contrastar com os pressupostos da abordagem de Lenoir. Várias passagens no restante deste texto são, sem uma referência mais precisa, partes extraídas e adaptadas do meu livro intitulado Condamner. Une analyse des pratiques pénales (Condenar. Uma análise de práticas penais) (KAMINSKI, 2015) (ver também Kaminski, 2016).

Muitas diferenças contextuais merecem ser mencionadas antes de qualquer coisa. O período não era o de uma revolta judicial por parte dos magistrados diante de alterações legislativas que se relacionavam precisamente com o assunto do inquérito e da investigação. Além disso, não passei pela hierarquia para "recrutar" meus interlocutores. Em vez disso, consegui com magistrados com os quais já tinha contato, provenientes de duas circunscrições diferentes, que entrassem em contato com seus colegas para perguntar-lhes se concordariam em participar do meu trabalho. Sem instruções, sem palavras de ordem, sem resistência então manifestada com relação àqueles que aceitaram participar do meu trabalho. Em vista das entrevistas obtidas, também posso apontar que minha amostra de interlocutores contém magistrados que provavelmente têm e não têm algum problema com a justiça. Isso se reflete nos dados obtidos, não nas modalidades de respostas ou de atitude, sempre acolhedora e aberta diante do pesquisador. Isso poderia ser um viés de amostragem? A esse respeito, encontrei magistrados que são muito diversos em termos de gênero, idade, convicções relativas a seu papel, ou ainda, em termos de referências culturais que evocam nas entrevistas.

Devemos acreditar que um criminólogo belga não é tão suspeito quanto um sociólogo francês? Devemos ler aqui a especificidade nacional - tão francesa - da conflitualização das posições sociais, da representação republicana das nobres profissões e das profissões que exercem e levantam suspeitas? As divisões internas da sociologia francesa e as divisões que atra- vessam a magistratura francesa são inegavelmente mais nítidas e mais agudas que as existentes na Bélgica. Eu não encontrei, durante a minha observação, nenhuma desconfiança, nem qualquer outra cautela diferente daquelas que são tomadas durante os primeiros encontros entre dois estranhos, compartiIhando, no entanto, uma posição social "respeitável". Mas isso não me impediu de encontrar as linhas de força de um ethos profissional semelhante aos traços da magistratura francesa conhecida por Lenoir.

Em parte, a diferença é certa no modo de abordagem e de contato. Mas o mais importante, parece-me, é a questão da pesquisa e as instruções da entrevista. Lenoir busca o descompasso. Ele está certo, e aqui concordamos, que a prática dos magistrados distancia-se das normas institucionais invocadas tanto defensiva quanto eticamente. Essa distância existe e ela é documentada por muitos resultados de pesquisa para cuja construção Lenoir contribuiu. Mas o que chamo de "sociologia do descompasso", que considera como vitoriosa a abordagem do pesquisador que conseguiu arrancar declarações que mostram esse descompasso, parece-me "pobre" ou "insuficiente". Eu me dei uma estratégia de pesquisa que, longe de buscar a todo custo o descompasso, permitiu revelar muitos aspectos sem, no entanto, ter procedido à extração, a fórceps, de confissões culpadas e sofridas de magistrados que teriam cedido devido ao seu "problema com a justiça”.

O meu problema com a sociologia do descompasso é que ela não escuta a prática ou sua narração pelo que ela é, em sua autonomia. Essa sociologia acredita, mais do que os magistrados talvez, que a lei é a norma, que o descompasso é escandaloso (e pode ser, certamente). Uma sociologia policial e corretiva emerge dessa obsessão pelo descompasso. Ela certamente informa, certamente ajuda a medir; mas seu projeto permanece correcionalista, como é o dos juízes. Essa simetria, que eu enfatizei, foi feita sintomaticamente pela fraternidade do sociólogo e do magistrado, compartilhando a mesma especialidade: o interrogatório. Longe de me considerar um especialista, manuseio a entrevista - não o interrogatório - e, se o questionamento dirigido aos juízes não estiver focado na diferença entre a norma e a prática, temos a oportunidade de descobrir, sem as 
defesas e as resistências encontradas por Lenoir, não apenas as possíveis diferenças, mas especialmente as próprias práticas (como são representadas na fala) e sua justificação. Em outras palavras, as resistências e os obstáculos dependem de uma maneira de fazer sociologia, informam sobre o habitus e a estratégia combativa do pesquisador tanto quanto, senão mais do que, o habitus dos magistrados.

Michel de Certeau (1990) descreveu como as práticas aparentemente mais insignificantes implementam artes de fazer que são também desvios normativos. 0 vínculo social aí se produz; uma norma é convocada. Mas aí se revela também o produto de táticas próprias para preservar a singularidade do autor anônimo da cultura cotidiana. As práticas são, por definição (com algumas exceções), desvios da norma. Quem melhor do que um sociólogo deve saber disso, observando-se no exercício de sua profissão? Esta definição torna possível, com novas consequências, entender por que uma "sociologia do descompasso" oferece (e não é um presente!) uma leitura normativa das práticas. A avaliação ou a indignação não são apropriadas, da mesma forma que elas não são apropriadas quando se tenta entender as chamadas práticas criminosas. De qualquer forma, uma atitude crítica completa exige esse ascetismo intelectual pragmático aplicado de forma equitativa a todas as práticas, independentemente da partição que os critérios de legitimidade asseguram. O conhecimento pode servir melhor à indignação quando esta não cega a priori o projeto de conhecer.

Pierre Bourdieu ainda sofrerá as consequências desta minha crítica: ele trata das condições de felicidade da entrevista. A felicidade, longe da neutralidade, pressupõe a aquisição de um ofício cujas habilidades são organizadas de tal maneira que o entrevistado entregue sua verdade, ou melhor, se liberte de sua verdade (Bourdieu, 1993, p. 920). A felicidade parece-me uma questão melhor do que o sucesso (o que parece muito a uma vitória do pesquisador). Mas essa verdade que seria o objetivo da abordagem sociológica, o que ela é? Aquela que foi extorquida sob o fascínio do descompasso? Aquela que foi utilizada para revelar os artifícios do aparelho jurídico? Aquilo que resuma as relações sociais entre o sociólogo e o magistrado: desconfiança, dificuldade de conivência, distanciamento jurídico, impossibilidade de se livrar do habitus insti- tucional e valores de independência, do serviço público ou do interesse geral, mesmo e especialmente para aqueles e aquelas que, por exemplo (Lenoir, 1996), denunciam a prisão preventiva como "punição imediata", "solução de conforto", "preconceito”?

Outra "verdade", que me parece inadmissível de nomear dessa maneira, está, portanto, em jogo. A identificação desse famoso descompasso entre norma legal e prática é o projeto secular de Roscoe Pound, que em 1910 escreveu:

"É o trabalho dos juristas de fazer com que a prática do direito (law-in-action) seja conforme o direito dos livros (law-in-books). Eles não o farão nem por meio de acusações violentas e fúteis contra as ilegalidades do povo, nem por meio de exortações eloquentes em favor da obediência à lei escrita, mas agindo de tal forma que o direito dos livros favoreça a conformidade da prática, oferecendo termos legais para sua aplicação que sejam rápidos, baratos e eficazes. Só a partir dessas condições é que law-in-books e law-in-action poderão ser reconciliados” (Pound, 1910).

A denúncia e o estreitamento do descompasso estão no cerne desse projeto e me parecem muito pouco sociológicos, independentemente dos métodos que possibilitem alcançá-los. A sociologia do descompasso, em seu trabalho de denúncia e correção, sustenta um ideal de reconciliação (muito improvável). Nessa empreitada, o sociólogo considera a lei como um jurista muito mais do que como um sociólogo, e sua adoração provavelmente leva um curso muito mais ortodoxo do que o dos próprios juristas. Ao culto implícito da lei corresponde este compromisso correcionalista das práticas, "felizmente" denunciadas pelos interlocutores graças a um sociólogo que será colocado a pensar em seu lugar...

A distinção conceitual de Roscoe Pound (1910) - muito bem sucedida ao longo do século - entre law-in-books e law-in-action apresenta, a este respeito, um duplo defeito epistemológico e semântico. Ela favorece uma representação "desviante" da ação (a norma estando no law-in-books) e, paradoxalmente, deixa entender que é todavia a lei que atua. É sociologicamente mais apropriado dar crédito à deforma- 
ção conceptual irônica law-inaction (da inação da lei) ou à fórmula mais precisa de action-with-law (ação com lei). Esta última permite compreender melhor 1) que os campos de ação tradicionalmente conferidos sob o nome de aplicação da lei são práticas de mobilização do recurso legal operado em conflito com outras normas (Lascoumes, 1990), na maioria das vezes organizacionais e profissionais (Monjardet, 1996) e 2) que é parte das práticas dos juízes o importante trabalho de justificação dos arbítrios entre o universo de normatividades concorrenciais e conflituais. Para esse trabalho de justificação, a lei oferece um serviço medíocre.

\section{O que é condenar? O que "condenar" faz dizer}

A perspectiva que respaldo torna possível compreender e justamente resistir à tendência "condenatória" da sociologia do descompasso. Medir os descompassos para corrigi-los é a atividade de um juiz, não de um pesquisador. Em vez de procurar o descompasso por ele próprio, vamos tentar compreendê-lo e, mais ainda, entender como os atores - que conhecem as suas práticas e os descompassos que estas possuem bem melhor do que os pesquisadores - conseguem compor algo com as normas que orientam as suas ações e a justificar essa composição. Para este fim, eu me dirigi aos juízes penais para lhes fazer uma pergunta simples, que escrevo numa formulação aparentemente ingênua:

"Creio saber, no papel de pesquisador, o que representa a ação de julgar e a ação de punir, mas o vocabulário jurídico usa uma palavra... E você também a usa muito regularmente nas formulações de seus julgamentos... Essa palavra é a palavra 'condenar'. Na verdade, eu me pergunto do que se trata. O que significa esta palavra?"

A questão da interação definitivamente não é mais, portanto, entre "especialistas em interrogatório", ou sobre "ter domínio sobre a definição do problema e de tentar impô-la ao outro" (Lenoir, 1996), mas sim de submeter ao interlocutor um problema que o pesquisador se dá e para o qual ele vem procurar o saber e a experiência/expertise de seus entrevistados. No entanto, a escolha da questão não é indiferente; ela envolve a sua parte de estratégia. A partir de um questionamento aos magistrados sobre o que quer dizer condenar, meu interesse se dirige certamente para as respostas fornecidas, mas também para o que o meu estímulo - o uso da palavra "condenar" faz dizer aos magistrados.

Assim, a instrução da entrevista imediatamente suscita vários sintomas que atestam o constrangimento e a recusa em assumir o uso da palavra: o tom, a hesitação na resposta, a expressão facial (um sorriso reconfortante parece dizer: "Isso não é tão ruim como você parece acreditar", enquanto eu usei apenas uma palavra sem expressar a carga que ela poderia ter para mim), o sinônimo eufemístico ("sancionar") ou a metáfora da punição dos pais dirigida às crianças, a preocupação de reduzir a condenação à sua dimensão expressiva (uma reação ao cruzamento de um limite, abstrato, válido para qualquer tipo de ilegalidade civil ou penal) são todas pistas concordantes de uma necessidade de se distanciar de um duplo encargo implicitamente contido (e explicitamente rejeitado) pela palavra "condenar": o ato de condenar é violento e definitivo.

Aqui está a resposta de um dos juízes, ininterrupta e imediatamente produzida após a apresentação das minhas instruções que acabei de apresentar

Eu absolutamente não me sinto como uma máquina de condenar, porque antes disso, há todo o processo que consiste em julgar, em tentar entender, estabelecer uma verdade que não será nunca somente a verdade judicial. Na conjuntura da sociedade atual, o juiz penal faz algo bem diferente do que condenar. Quando vejo o número de decisões de simples declaração de culpabilidade, de suspensão de aplicação da pena... Bem, a pena de trabalho é uma condenação, mas é uma condenação com efeito útil: quando nós a aplicamos, não é para fazer mal, para condenar... é para marcar uma certa reprovação, mas ao aplicá-la não se tem a impressão de condenar, especialmente porque isto é feito com a concordância da pessoa que recebe essa sanção. Então, para mim, a condenação ocorre quando eu sentencio com uma pena de prisão em meio fechado, que provavelmente será executada. Quando digo isso, é verdade, sinto que estou realmente condenando. 
Mas isso não me traz verdadeiramente um problema porque eu sei que estou investido pela sociedade dessa missão, dessa faculdade. E se eu condeno é porque eu acho que tenho que fazê-lo, acho que é a coisa mais justa. Mas tenho a impressão que é quase um aspecto secundário da minha atividade. Eu não me sinto absolutamente uma máquina de condenar. É verdade que eu condeno, condeno, mas quando condenamos, fazemos mais do que isso; há todo o processo antes disso que é esse de compreender, de fazer compreender; uma decisão nunca é uma condenação pura. Eu acredito que o cara que toma consciência de que ele é condenado, também aprende o porquê, ele não lembra apenas da condenação em si; uma certa verdade é restaurada, e em muitos casos até aprovada. Não é incomum ter diante de si alguém que conteste os fatos com bastante veemência, e depois, no dia do julgamento em que se pronuncia a sentença, ele geralmente aceita isso; ele finalmente sente que nós entendemos as coisas e que uma boa decisão foi tomada em vez de uma condenação que seria pura, brutal. É um termo que eu uso pouco, finalmente, condenação. Eu não sinto que eu seja alguém que condene, mesmo que eu seja obrigado a fazê-lo.

Essa longa sequência distingue seu conteúdo em duas questões: a definição (primeiro parágrafo) e a justificação (segundo parágrafo). É evidente que esse juiz condena a cada audiência muitos acusados e ninguém o censura por isso. Mas esse ponto de negação - qualquer que seja sua interpretação - não interessa muito. É importante compreender a definição original e restritiva da palavra para perceber em seguida a justificativa dada pelo juiz de sua recusa em aderir à sua definição legal ou institucional.

As modalidades de distanciamento - negação e eufemismo - em relação à gravidade da palavra são múltiplas (...): carregá-la negativamente, negando o uso legal, qualificá-la com outra conotação ambígua, dar-lhe um lugar secundário. A modalidade mais significativa e transversal será encerrá-la entre duas missões profissionais mais facilmente definíveis (que minhas instruções, no entanto, tentam descartar): julgar e punir. Todos esses mecanismos de distanciamento levam os juízes a um uso eufemístico da pala- vra, forçado pela instrução da entrevista.

Mas é importante significar que a suspeição, a cautela e a resistência não são dirigidas ao pesquisador, mas manifestam-se em relação ao objeto examinado, o que, no entanto, não tem motivo, a priori, para produzir o menor reflexo defensivo. O pesquisador, longe de ser um estranho, compartilha um assunto de estranheza com seus interlocutores. Isso não impede, de modo algum, a expressão de fenômenos analisáveis de maneira bastante próxima dos propósitos de Lenoir, mas sem passar pelo desvio de uma relação intersubjetiva apresentada como um combate a ganhar ou a perder.

A dificuldade encontrada diante da palavra/objeto da pergunta inicial conduz o entrevistado a revelar os mecanismos pelos quais a negação e a eufemização se justificam. É então que emergem elementos de comparação entre diferentes disputas e entre os estereótipos de seus autores. Neste caso, o quadro apresentado abaixo (extraído de Kaminski, 2015) leva a partir de uma tipificação a compreender os vetores de "impotência" ou do impasse de seus respectivos tratamentos. A tabela sintetiza a análise, categorizando os fatos julgados e seus autores em suas quatro primeiras linhas, reservando à quinta a consequência que os juízes extraem dessa tipificação. Permite compreender, no entrelaçamento das representações que aparecem em cada linha, as razões pelas quais se condenam poucos autores de disputas financeiras. Embora ausentes na audiência, estão dentro da normalidade e são racionais, sem antecedentes, então são pouco condenados, ainda mais porque gostaríamos que de fato fossem condenados. Uma impotência técnica para condenar muitas vezes surge da complexidade do caso, tendo em vista os múltiplos meios de defesa do acusado. Ao contrário, os autores de infrações comuns, condenados um tanto a contragosto, são representados como indivíduos fora da sociedade, reincidentes, cuja presença na audiência (sem defesa e sem estratégia adequadas) afeta negativamente o juiz e cuja racionalidade, finalmente, é suposta (às vezes contra todas as probabilidades).

O impasse observado regularmente nos comentários dos juízes apresenta efeitos contrários: o impasse é social para os litígios comuns (levando a condenações 
“obrigadas", por vezes lamentáveis), e processual para o direito penal econômico (levando a absolvições técnicas, além de decisões indulgentes devido à notabilidade e à racionalidade da classe de infratores primários).

\begin{tabular}{|c|c|c|}
\hline $\begin{array}{l}\text { Suporte de cate- } \\
\text { gorização }\end{array}$ & $\begin{array}{l}\text { Autores de infra- } \\
\text { ções financeiras }\end{array}$ & $\begin{array}{l}\text { Autores de infrações } \\
\text { "comuns" }\end{array}$ \\
\hline $\begin{array}{l}\text { Identidade dos } \\
\text { acusados }\end{array}$ & $\begin{array}{l}\text { Atores econômicos } \\
\text { "dentro da norma- } \\
\text { lidade" }\end{array}$ & $\begin{array}{l}\text { Indivíduos precários } \\
\text { "fora da sociedade" }\end{array}$ \\
\hline $\begin{array}{l}\text { Relação ao com- } \\
\text { parecimento do } \\
\text { acusado na audi- } \\
\text { ência }\end{array}$ & $\begin{array}{l}\text { Ausentes } \\
\text { Salvo exceções }\end{array}$ & $\begin{array}{l}\text { Presentes } \\
\text { Afetação do juiz }\end{array}$ \\
\hline $\begin{array}{l}\text { Racionalidade } \\
\text { dos autores }\end{array}$ & $\begin{array}{l}\text { Reconhecida e } \\
\text { conhecida }\end{array}$ & $\begin{array}{l}\text { Suposta abstrata- } \\
\text { mente }\end{array}$ \\
\hline Carreira penal & "Réus primários" & $\begin{array}{l}\text { Reincidentes ou } \\
\text { com risco de reinci- } \\
\text { dência }\end{array}$ \\
\hline $\begin{array}{l}\text { Impotência do } \\
\text { juiz }\end{array}$ & Técnica & Social ou moral \\
\hline
\end{tabular}

Esses resultados "clássicos" são menos importantes aqui do que a questão de saber como nós os obtivemos. O mal-estar cognitivo produzido pela palavra "condenar" convida os entrevistados a produzir uma justificação de sua atividade, levando-os a observações que não são confissões nem espontâneas nem arrancadas, nem expressões do "inexprimível”, nem "catarse" "(Lenoir, 1996). O desconforto cognitivo ao qual expõe a palavra "condenar" impõe aos magistrados contextualizações que levam em conta as dificuldades de sua experiência e lógicas sociais de seu trabalho. Esses resultados são dependentes da confrontação com uma palavra pertencente ao seu mundo e não de sua confrontação com um projeto de denúncia proveniente do mundo do pesquisador.

\section{In cauda venenum: de volta à distancia social}

Tenho um último ponto a discutir, sempre em suporte contrastante sobre os apontamentos de Lenoir. Entrevistas realizadas com jovens delinquentes mostraram, já há algum tempo, como os jovens em questão "aprendem a delinquência" igualmente em seus contatos com o sistema de justiça. David Matza, em Delinquency and Drift (1964), argumenta que "quanto mais um indivíduo estiver em contato com uma instituição encarregada de aplicar a lei, mais ele está em posição de minimizar a força moral da lei. É por isso que o processo de neutralização é tecido na trama do próprio sistema jurídico".

Os juízes parecem agir da mesma forma que os infratores, apesar da legitimidade de suas práticas. Os juízes não precisam, num plano institucional, se justificar ou neutralizar os efeitos morais de suas práticas: estas são legítimas. Mas quando perguntados sobre o que é condenar, suas respostas incluem muitas proposições comparáveis às formas de neutralização encontradas em jovens delinquentes (Sykes e Matza, 1957). Essas formas são as seguintes. A negação de responsabilidade: o contexto da profissão (a lei), o sistema, o registro do seu trabalho do início ao fim, explicam e desculpam as práticas "obrigatórias" dos juízes. A negação da culpa: a condenação (como um ato) é inofensiva, benigna, prejudica apenas ligeiramente sua "vítima". A negação da vítima: o condenado não é realmente um condenado, uma vez que ele sofre uma forma justa, uma reação merecida (que ele concorda e que, às vezes, pela qual ele agradece seu juiz). A condenação daqueles que condenam: aqui são visados os atores políticos, quando eles votam leis injustas e os atores, às vezes "hipócritas", os processos penais. A invocação a lealdades superiores: o legalismo é às vezes misturado com uma lealdade referente a valores graças aos quais os critérios sociais de divisão do mundo (aqueles que a lei respeita) são não apenas renovados, mas também apoiados.

A identificação dessas modalidades de neutralização permite reformular a questão da intersubjetividade na entrevista. Um lugar comum antropológico ao qual subscrevo servirá de ponto de partida. François Bonnet indica que a distância social entre entrevistador e entrevistado é "imaginada e fantasiada", "antes de ser vivida” (Bonnet, 2008, p. 65). Ele também argumenta que a distância social não é um atributo, e que ela varia de acordo com as habilidades culturais e estratégicas do pesquisador e de seus entrevistados. Bonnet continua: "Não é necessário que os entrevistados nos 'aceitem plenamente' ou 'confiem em nós'” (Bonnet, 2008, 69). Em outras palavras, o sucesso ou a felicidade de uma interação de pesquisa, evocada 
por referência a Lenoir e Bourdieu, não são critérios muito bons de riqueza ou produtividade da entrevista. A capacidade do pesquisador de distinguir entre a missão e a atividade dos juízes merece ser aplicada a ele reflexivamente. A atividade da entrevista não é a missão que santifica o manual de metodologia: ela também consiste em questionar a própria atitude ou a representação que os entrevistados têm, sobre seu próprio regime de justificação, e como ele pode ser refletido pelos jogos de distância social que os pesquisadores deveriam ser tão capazes de fazer quanto seus entrevistados.

A descoberta pelo analista dos processos de neutralização nos juízes que ele conheceu não significaria que, para seus entrevistados, o objeto da entrevista era objeto de avaliação? Um significante certamente, mas um significante do mal, do mal institucional e legítimo do qual eles estão encarregados profissionalmente? E, a partir desse momento, impondo-lhes esse significante, o pesquisador não se tornou seu juiz? Em caso afirmativo, a hierarquia das credenciais profissionais ou identificações ativas na entrevista não são as que Lenoir considerou (as do pesquisador chamado a se apresentar à altura). Por outro lado, elas estão invertidas: ao me apresentar como interessado em entender a significação/significado de uma palavra, eu, nas idas e vindas da distância social, tornei-me juiz do "crime" que ele designa e da justificação que ele exige. Se colocar em pensamento no lugar do outro? Os investigados são tão capazes quanto o pesquisador. A “má consciência” eles têm, aqui ou ali, mas ela não é o motor de uma boa entrevista. Ela é, entre outros, uma alavanca de uma palavra, exercendo uma influência em diversos níveis de distância social, especialmente se essa alavanca não foi imposta pelo pesquisador. A conivência está presente, mas talvez ela represente menos a dor profissional ("problema com a justiça") do que a dificuldade espelhada de se sentir julgado (condenado?) pelo pesquisador.

HIIIIIIIIIIIIIIIIIIIIIIIIIIIIIIIIII

\section{Referências}

Akrich M., Callon M., Latour B. (eds), 2006, Sociologie de la traduction : textes fondateurs, Paris, Presses des Mines.

Boltanski L. (entretien avec F. Delmotte et C. Lavergne), 2013, "De la sociologie de la critique aux impasses actuelles de la critique sociale", in Cukier A., Delmotte F., Lavergne C. (dir.), Émancipation. Les métamorphoses de la critique sociale, Broissieux, Éd. du Croquant, pp. 31-60.

Boltanski L., Thévenot L., 1991, De la justification. Les économies de la grandeur, Paris, Gallimard.

Bonnet Fr., 2008, "La distance sociale dans le travail de terrain : compétence stratégique et compétence culturelle dans l'interaction d'enquête", Genèses, $n^{\circ} 73,4$, pp. 57-74.

Bourdieu P., 1993, La misère du monde, Paris, Seuil.

Certeau M. (de), 1990, L'invention du quotidien. 1. Arts de faire, Paris, Gallimard, Folio Essais.

Corcuff Ph., 2007, Les nouvelles sociologies. Entre le collectif et l'individuel, Armand Colin, coll.128.

Kaminski D., 2015, Condamner. Une analyse des pratiques pénales, Toulouse, Éres.

Kaminski D, 2016, Des objets impénétrables à la connaissance ou des chercheurs rendus impuissants par leur désir de dévoilement?, Revue internationale de criminologie et de police technique et scientifique, $\mathrm{n}^{\circ} 3$, pp.277-288.

Lagasnerie G. (de), 2016, Juger. L'État pénal face à la sociologie, Paris, Fayard.

Lascoumes P., 1990, Normes juridiques et mise en œuvre des politiques publiques, L'année sociologique, $\mathrm{n}^{\circ} 40$, p. 43-71.

Lenoir R., 1996, "Le sociologue et les magistrats. Entretiens sur la mise en détention provisoire", Genèses, $n^{\circ} 22$, pp. 130-145.

Olivier de Sardan J.-P., 2008, La rigueur du qualitatif. Les contraintes empiriques de l'interprétation socio-anthropologique, Louvain-la-Neuve, Academia-Bruylant.

Matza D., 1964, Delinquency and Drift, New York, Wiley.

Monjardet D., 1996, Ce que fait la police. Sociologie de la force publique, Paris, La découverte.

Roscoe Pound N., 1910, "Law in books and law in action", American Law Review, 44, pp. 12-36.

Sykes G.M., Matza D., 1957, "Techniques of neutralization. A theory of delinquency", American Sociolo- 
gical Review, 22, pp. 664-670.

Weller J.-M., 1994, “Le mensonge d'Ernest Cigare : problèmes épistémologiques et méthodologiques à propos de l'identité", Sociologie du travail, Vol $36, n^{\circ} 1$, pp. 25-42.

Data de submissão/Submission date: 30.12.2016.

Data de aceitação para publicação/Acceptance date: 01.10.2017. 